\title{
ORGANISMOS GENÉTICAMENTE MODIFICADOS Y RECONOCIMIENTO DE DERECHOS INDÍGENAS: ANÁLISIS DE LA SENTENCIA DE AMPARO 753/2012 DEL JUZGADO SEGUNDO DE DISTRITO EN EL ESTADO DE CAMPECHE
}

\author{
Genetically modified organisms and recognition of native's rights: analysis of the \\ judgment given in Amparo 753/2012 at the second court of law on the \\ district in the state of Campeche
}

\author{
Gloria Aurora DE LAS FUENTES LACAVEX ${ }^{1}$ \\ Alejandro SÁNCHEZ SÁNCHEZ ${ }^{2}$ \\ René Alberto CASTRO RAZCÓN ${ }^{3}$
}

\begin{abstract}
Sumario:
I. Introducción. II. Antecedentes históricos y jurídicos de los organismos genéticamente modificados. III. Reconocimiento de Derechos Indígenas. IV. Derecho a un medio ambiente sano. V. Análisis de la sentencia del juicio de amparo 753/2012 del Juzgado Segundo de Distrito en el Estado de Campeche. VI. Conclusiones y propuestas. Fuentes
\end{abstract}

Resumen. Los organismos genéticamente modificados, implican muchísimas ventajas para la economía y la alimentación, sin embargo se desconocen sus posibles efectos en la salud y el medioambiente; lo que se relaciona con la obligación del Estado de garantizar que el desarrollo nacional sea integral y sustentable. Las autorizaciones que el Estado otorga sobre la liberación al ambiente, de estos organismos, deben estar supeditadas al derecho a un medio ambiente sano y la participación de las comunidades indígenas en la determinación de politicas que permitan el uso y disfrute preferente de los recursos naturales de los lugares que habitan.

Palabras Clave: OGM. Derechos Indígenas. Medio ambiente.

Abstract. Genetically modified organisms, imply many economic and alimentation advantages, yet the possible effects on health and the environment remain unknown, which is related to the State's obligation to ensure that national development is thorough and sustainable. The authorizations granted by the State on the environmental release of GMO, should be subject to the right to a healthy environment and the participation of indigenous communities in

1 Doctora en Derecho, Perfil Promep, Miembro del Sistema Nacional de Investigadores Nivel I, Profesor Investigador de la UABC, adscrita a la Facultad de Ciencias Administrativas y Sociales de la UABC, gloriaaurora@uabc.edu.mx

2 Doctor en Derecho, Perfil Promep, Miembro del Sistema Nacional de Investigadores Nivel I, Profesor Investigador de la UABC, adscrito a la Facultad de Ciencias Administrativas y Sociales de la UABC, alexsasacc@ uabc.edu.mx

3 Egresado de la Licenciatura en Derecho en la Facultad de Ciencias Administrativas y Sociales de la UABC. 
determining policies that allow their preferential use of natural resources of the places they inhabit.

Keywords: GMO. Indigenous rights. Environment.

\section{INTRODUCCIÓN}

La aplicación de biotecnología y modificación del ADN, generando Organismos Genéticamente Modificados (OGMs), tiene por finalidad la mejora de la productividad de las semillas, capacidad de resistencia a plagas, herbicidas, y/o condiciones climáticas, es decir, incrementar la productividad de la siembra; producir más en menos tiempo y/o terreno agrícola.

En México, en 1988, la primera solicitud para importar y liberar en campo, organismos genéticamente modificados, inició la necesidad de apoyo al sector oficial en la toma de decisiones sobre dichas solicitudes.

Actualmente el Consejo Nacional de Ciencia y Tecnología (CONACYT), cuenta con una Comisión Intersecretarial de Bioseguridad de los Organismos Genéticamente Modificados (CIBIOGEM), formada con representantes de las secretarías de Agricultura, Ganadería, Desarrollo Rural, Pesca y Alimentación (SAGARPA), Ambiente y Recursos Naturales (SEMARNAT), Salud (SSA), Economía (SE), Hacienda y Crédito Público (SHCP), y Educación (SEP), cuya actividad de mayor relevancia es, en aplicación del Principio de Derecho Ambiental de Prevención, evaluar el uso de OGMs, para coordinar políticas federales relativas a su producción, exportación, movimiento, propagación, liberación y consumo.

Desde la entrada en vigor de su publicación en el Diario Oficial de la Federación (DOF) de 14 de agosto de 2001, el artículo $2^{\circ}$ constitucional, reconoce que México tiene una composición pluricultural sustentada originalmente en sus pueblos indígenas, mismos que ejercen un derecho a la libre determinación en un marco constitucional de autonomía que asegure la unidad nacional; reconociendo su derecho al uso y disfrute preferente de los recursos naturales de los lugares que habitan; y considerando la necesidad de establecer instituciones y determinar políticas necesarias para garantizar la vigencia de los derechos de los indígenas y el desarrollo integral de sus pueblos y comunidades, mismas que deben ser diseñadas y operadas conjuntamente con ellos.

A partir del inicio de la vigencia de la publicación en el DOF de 28 de junio de 1999, según el artículo $4^{\circ}$ constitucional se reconoce a toda persona el derecho a un medio ambiente sano para su desarrollo y bienestar; mientras que con una reforma -adición a este ordenamiento a partir del 9 de febrero de 2012-, se reconoce la obligación del Estado de garantizar el respeto a este derecho.

Con la entrada en vigor de la reforma al artículo 25 constitucional publicada en el DOF de 3 de febrero de 1983, se adjudica al Estado mexicano, por mandato constitucional, la obligación de garantizar que el desarrollo nacional sea integral y sustentable.

Acciones judiciales como la del amparo otorgado a una comunidad indígena, frente al permiso otorgado a Monsanto ${ }^{4}$ para la explotación de semillas de OGMs promueven el de-

\footnotetext{
${ }^{4}$ Empresa proveedora de productos químicos para la agricultura y semillas transgénicas. Entre sus productos más conocidos se encuentran el glifosato bajo la marca Roundup y el maíz genéticamente modificado $M O N$ 810. Genera polémicas, debido a múltiples denuncias sobre perjuicios a la salud, impactos ambientales negativos y el desconocimiento acerca de los efectos que podría producir la alteración genética de los alimentos. 
Organismos genéticamente modificados y reconocimiento de derechos indígenas: análisis de la sentencia de amparo 753/2012 del juzgado segundo de Distrito en el Estado de Campeche

sarrollo sustentable, el derecho a un medio ambiente sano y la participación de las comunidades indígenas en la determinación de políticas que permitan el uso y disfrute preferente de los recursos naturales de los lugares que habitan, pues aseguran que una comunidad pueda seguir empleando sus semillas, métodos ancestrales y conocimientos que garantizan la correcta utilización de los recursos.

Mientras que acciones legislativas como la de la modificación al reglamento de SEMARNAT, se presentan contrarias a esta idea, pues eliminar la obligatoriedad de atender las opiniones y recomendaciones emitidas por las autoridades correspondientes y fundadas en análisis científicos, relativas a la idoneidad o conveniencia de la emisión de permisos (autorizaciones, concesiones o licencias), concernientes a la utilización y/o explotación de recursos naturales, resulta absurdo pues implica pérdida o desperdicio de recursos tanto humanos como económicos, por la realización (y financiamiento) de estudios que no serán atendidos, así como la innecesaria afectación a los recursos naturales que garantizan nuestra subsistencia.

\section{ANTECEDENTES HISTÓRICOS Y JURÍDICOS DE LOS ORGANISMOS GENÉTICAMENTE MODIFICADOS}

Según la Organización Mundial de la Salud (OMS) los organismos genéticamente modificados (OGM) pueden definirse como organismos en los cuales el material genético, ácido desoxirribonucleico (ADN), ha sido alterado de un modo artificial. La tecnología generalmente se denomina biotecnología moderna o tecnología genética, en ocasiones también tecnología de ADN recombinante o ingeniería genética. Ésta permite transferir genes seleccionados individuales de un organismo a otro, también entre especies no relacionadas, ${ }^{5}$ básicamente de este modo partes del ADN de un ser vivo, ya sea bacteria, virus, vegetal, animal, puede ser separado, modificado y transferido para alojarse en otro, no necesariamente del mismo tipo. Estas mezclas se realizan para crear plantas comestibles que posteriormente se cultivarán comercialmente, por lo cual resulta de suma relevancia el análisis de la aplicación de dicha tecnología en los alimentos, por las consecuencias que pudieran generarse en las personas, en el medio ambiente y en la economía.

Uno de los objetos de la aplicación de la biotecnología y la modificación del ADN reside en la importancia de mejora de la productividad de las semillas, en la capacidad de resistencia a diferentes plagas, herbicidas, y/o condiciones climáticas; por tal motivo, la finalidad de dichas técnicas especializadas es incrementar la productividad de la siembra, disminuyendo por tanto el espacio, o fertilizantes necesarios; coloquialmente hablando producir más en menos tiempo y/o terreno agrícola.

Respecto a los OGMs, la situación, puede ser analizada desde diferentes perspectivas: tal es el caso de la necesidad de incremento en la producción de los campos agrícolas en México. La modificación del ADN de las semillas, puede generar un mayor aprovechamiento, generando mejores beneficios económicos al productor, al contar con mejor calidad y mayor cantidad de producto que colocar en el mercado, logrando aumentar la disponibilidad de

\footnotetext{
${ }^{5}$ http://www.who.int/foodsafety/areas_work/food-technology/faq-genetically-modified-food/en/\# 4 de agosto de 2015. Tradución propia.
} 
alimentos, considerando que a mayor producción los costos y por tanto los precios tienden a ser menores, de modo tal que se genera un beneficio para la población.

En este orden de ideas y en atención al rendimiento de producción de los OGMs es clara la posibilidad, para los agricultores de una mejora económica que pudiera aportar elementos necesarios permitiendo un mayor consumo y por tanto impulsando, aumentando y mejorando la economía de los estados que implementen dichas medidas; eso sin dejar de lado la perspectiva social, siendo que los estados en general pueden aprovechar el mayor rendimiento de la producción, con semillas OGMs para lograr una solución, erradicando los problemas de alimentación a nivel mundial.

Todo lo anterior presenta el enfoque positivo, o las ventajas que los OGMs nos proporcionan; sin embargo también existe incertidumbre y preocupación en algunos sectores de la población, que consideran la necesidad de analizar y evaluar toda aplicación biotecnológica, en tanto, desconocemos sus posibles efectos a la salud humana o la medio ambiente.

Como tema relevante para la comunidad internacional, este fenómeno científico, no podía quedar fuera de la regulación jurídica y como antecedente de tal, encontramos que se completó el texto del Convenio sobre la Diversidad Biológica en Nairobi en mayo de 1992 y éste quedó abierto a la firma el 5 de junio de 1992 en Río de Janeiro en la Conferencia de las Naciones Unidas sobre el Medio Ambiente y el Desarrollo (UNCED). El Convenio entró en vigor el 29 de diciembre de $1993 .{ }^{6}$ Dicho convenio tiene por objetivo centrarse:

[... ]específicamente en el movimiento transfronterizo de cualesquiera organismos vivos modificados resultantes de la biotecnología moderna que puedan tener efectos adversos para la conservación y la utilización sostenible de la diversidad biológica, que establezca en particular, para su examen, procedimientos adecuados para un acuerdo fundamentado previo $[\ldots]^{7}$

Continuando con el interés ambiental, el Protocolo de Cartagena sobre Seguridad de la Biotecnología del Convenio sobre la Diversidad Biológica, cuya entrada en vigor internacional es el 11 de septiembre de 2003, ordena la adopción normas y procedimientos internacionales en la esfera de la responsabilidad y compensación por daños resultantes de los movimientos transfronterizos de organismos vivos modificados. ${ }^{8}$

Asimismo resulta necesario hacer especial mención de los efectos en el medio ambiente de los OGMs y nos encontramos con el primer problema ambiental debido a que es posible que pasen años o decenios antes de que se comprendan las consecuencias de los nuevos elementos biológicos en los ecosistemas; ${ }^{9}$ a partir de dicha premisa, es dable señalar que debe de ser extremadamente limitada o nula la posibilidad de que se extiendan las licencias y/o permisos para su comercialización, en virtud de que es necesario un plan estratégico para prevenir el impacto ambiental que puedan tener.

Algunas consecuencias de la producción industrial y utilización de OGMs que se estiman posibles son:

\footnotetext{
${ }^{6}$ https://www.cbd.int/doc/legal/cartagena-protocol-es.pdf 1 de agosto de 2015.

7 Ídem.

8 http://proteo2.sre.gob.mx/tratados/archivos/PROT_CARTAGENA.pdf 4 de agosto de 2010.

9 ftp://ftp.fao.org/docrep/fao/oo3/x96o2s/x9602soo.pdf 1 de agosto de 2015. 
Organismos genéticamente modificados y reconocimiento de derechos indígenas: análisis de la sentencia de amparo 753/2012 del juzgado segundo de Distrito en el Estado de Campeche

[... ] efectos imprevistos sobre la dinámica de las poblaciones en el medio receptor como resultado de los efectos sobre especies no destinatarias, que pueden producirse directamente - por predación o competición - o indirectamente - por cambios en el uso de la tierra o en las prácticas agrícolas-; efectos imprevistos en la biogeoquímica, especialmente debido a las repercusiones sobre las poblaciones microbianas del suelo que regulan el flujo de nitrógeno, fósforo y otros elementos esenciales; $[\ldots]^{10}$

En México la historia jurídica de los OGM's comienza en 1988: [... ] año en el que se presentó ante la Dirección General de Sanidad Vegetal (DGSV) la primera solicitud para importar y liberar en campo, específicamente en el área de Culiacán, Sinaloa tomate con la característica de resistencia a insectos, solicitud que fue aprobada y que dio la pauta para iniciar la formación de un grupo de expertos que apoyaran al sector oficial en la toma de decisiones sobre futuras solicitudes de experimentación de estos productos. En 1989 se formó el Comité Nacional de Bioseguridad Agrícola (CNBA), denominado posteriormente como Subcomité Especializado en Agricultura (SEA), el cual fungió como grupo asesor que apoyaba a la DGSV en la evaluación de la información sobre solicitudes para la liberación en campo de productos genéticamente modificados; así como en el establecimiento de regulaciones y políticas relacionadas con el tema. ${ }^{11}$

Actualmente en México la Comisión Intersecretarial de Bioseguridad de los Organismos Genéticamente Modificados (CIBIOGEM), que forma parte del Consejo Nacional de Ciencia y Tecnología (CONACYT), que cuenta con representantes de las secretarias de Agricultura, Ambiente y Recursos Naturales, Salud, Economía, Hacienda y Educación.

Una de las actividades de mayor relevancia encomendadas a esta comisión, es la de evaluar el uso de OGMs y los productos derivados de ellos; así como la coordinación de las políticas federales relativas a la producción, exportación, movimiento, propagación, liberación y consumo de los OGMs. Actividades que son una clara aplicación del principio de prevención que suele denominarse también como principio de cautela, pues ante la amenaza de daños, considerados suficientemente serios, al medio ambiente o la salud humana no es necesario esperar alcanzar una certidumbre científica completa para tomar las medidas protectoras

Como respuesta a los compromisos adquiridos en virtud de nuestra adhesión a la Convención sobre la Diversidad Biológica y al Protocolo de Cartagena sobre Seguridad de la Biotecnología del Convenio sobre Diversidad Biológica, fue publicada en el DOF el 18 de marzo de 2005, la Ley de Bioseguridad de Organismos Genéticamente Modificados LBOGM, para entrar en vigor a los treinta días hábiles de su publicación; el 19 de marzo de 2008, se publica en el DOF, el Reglamento de la Ley de Bioseguridad de Organismos Genéticamente Modificados, que entró en vigor al día siguiente de su publicación, cuya más reciente reforma se publicó en el DOF de 6 de marzo de 2009.

En dicho ordenamiento se regula: el procedimiento de la solicitud de permisos para la realización de actividades con OGMs, los requisitos para los permisos de liberación al ambiente; la reconsideración de resoluciones negativas y revisión a permisos y autorizaciones; la importación y exportación de OGMs destinados a liberación al ambiente; las comisiones internas de bioseguridad; los comités técnicos científicos; el Sistema Nacional de Información sobre Bioseguridad; las listas de OGMs; la inspección vigilancia, medidas de seguridad

\footnotetext{
10 Ídem.

${ }^{11}$ http://www.senasica.gob.mx/?id=2403 14 de agosto de 2015.
} 
o de urgente aplicación y las infracciones y sanciones; así como un régimen de protección especial del maíz.

\section{RECONOCIMIENTO DE DERECHOS INDÍGENAS}

A nivel internacional el Convenio 169 sobre pueblos indígenas y tribales en países independientes, de la Organización Internacional del Trabajo (OIT), aprobado en la Sesión 76 de la Conferencia Internacional del Trabajo el 27 de junio de 1989, es un instrumento convencional de naturaleza internacional vinculante para los estados que lo ratifiquen. Nuestro país llevó a cabo la ratificación de dicho instrumento el 5 de septiembre de 1990, entrando en vigor doce meses después, según lo dispuesto por el artículo 38 del propio Convenio publicado en el DOF de 24 de enero de 1991.

Este convenio formado por 44 artículos; establece (entre los artículos $1^{\circ}$ al 19), entre otras disposiciones: el ámbito de aplicación, el que los pueblos indígenas deben gozar plenamente de los derechos humanos y libertades fundamentales, el que deben adoptarse las medidas necesarias para salvaguardar las personas, las instituciones, los bienes, el trabajo, la cultura y el medio ambiente de los pueblos indígenas, la obligación de los estados de consultar a estos pueblos cada vez que se prevean medidas legislativas o administrativas susceptibles de afectarles directamente, que los gobiernos deben respetar la importancia especial que reviste la relación con las tierras o territorios para las culturas y pueblos indígenas, en particular los aspectos colectivos de esa relación, que deberán protegerse especialmente los derechos de los pueblos interesados sobre los recursos naturales existentes en sus tierras. Son de destacarse especialmente los artículos 8, 13, 14, 15 y 33.

El primero de éstos hace referencia que al aplicarse la legislación nacional a los pueblos interesados deberán tomarse en consideración sus costumbres o su derecho consuetudinario, que dichos pueblos deberán tener el derecho de conservar sus costumbres e instituciones propias, siempre que éstas no sean incompatibles con los derechos fundamentales definidos por el sistema jurídico nacional ni con los derechos humanos internacionalmente reconocidos. En caso necesario deberán establecerse procedimientos para solucionar los conflictos que puedan surgir en la aplicación de este principio.

El documento en comento, reconoce en su artículo 13, que el término tierras incluye el concepto de territorios, lo que cubre la totalidad del hábitat de las regiones que los pueblos interesados ocupan o utilizan de alguna manera. Mientras que el artículo 14 establece que deberá reconocerse a los pueblos interesados al derecho de propiedad y de posesión sobre las tierras que tradicionalmente ocupan. Adicionalmente en los casos apropiados, deberán tomarse medidas para salvaguardar el derecho de los pueblos interesados en utilizar tierras que no estén exclusivamente ocupadas por ellos, pero a las que hayan tenido habitualmente acceso para sus actividades tradicionales y de subsistencia.

Los derechos de los pueblos interesados a los recursos naturales existentes en sus tierras deberán protegerse especialmente. Estos derechos comprenden el derecho de esos pueblos a participar en la utilización, administración y conservación de dichos recursos, según lo dispone el artículo 15.1.

El último de los mencionados determina que la autoridad gubernamental responsable de las cuestiones que abarca el convenio deberá asegurarse de que existan instituciones o mecanismos apropiados para administrar los programas que afecten a los pueblos interesados, incluyendo la planificación, coordinación, ejecución y evaluación, de las medidas previstas 
en el propio convenio y la proposición de medidas legislativas y de otra índole a las autoridades competentes y el control de la aplicación de las medidas adoptadas en cooperación con los mismos.

A nivel nacional, el artículo 20 de la Constitución Política de los Estados Unidos Mexicanos (CPEUM), establece que México tiene una composición pluricultural sustentada originalmente en sus pueblos indígenas que son aquellos que descienden de poblaciones que habitaban en el territorio actual del país al iniciarse la colonización y que conservan sus propias instituciones sociales, económicas, culturales y políticas, o parte de ellas. Asimismo, determina que los pueblos indígenas ejercerán su derecho a la libre determinación en un marco constitucional de autonomía que asegure la unidad nacional. El reconocimiento de los pueblos y comunidades indígenas se hará en las constituciones y leyes de las entidades federativas, las que deberán tomar en cuenta, además de los principios generales establecidos en los párrafos anteriores de este artículo, criterios etnolingüísticos y de asentamiento físico.

El apartado A de este numeral, preceptúa en la fracción VI que los pueblos indígenas tiene autonomía para acceder, con respeto a las formas y modalidades de propiedad y tenencia de la tierra establecidas en la Constitución y las leyes de la materia, así como a los derechos adquiridos por terceros o por integrantes de la comunidad, al uso y disfrute preferente de los recursos naturales de los lugares que habitan las comunidades, salvo aquellos que corresponden a las áreas estratégicas, en términos de la Constitución. Para estos efectos las comunidades podrán asociarse en términos de ley.

El apartado B de este mismo artículo dispone que la Federación, estados y municipios, para promover la igualdad de oportunidades de los indígenas y eliminar cualquier práctica discriminatoria, establecerán las instituciones y determinarán las políticas necesarias para garantizar la vigencia de los derechos de los indígenas y el desarrollo integral de sus pueblos y comunidades, las cuales deberán ser diseñadas y operadas conjuntamente con ellos; mientras que la fracción VII del párrafo noveno del artículo 27 constitucional establece que la ley protegerá la integridad de las tierras de los grupos indígenas.

\section{DERECHO A UN MEDIO AMBIENTE SANO}

Con posterioridad a la Segunda Guerra Mundial, las constituciones de algunos países establecieron al medio ambiente como un objeto de protección, implantando como función del Estado la obligación de velar por la protección del mismo, además de considerar derecho de todo habitante, el de contar con un medio ambiente adecuado.

En relación con el derecho de todos a un medio ambiente apropiado para su desarrollo, encontramos que las constituciones de Nicaragua, Paraguay, Perú, Uruguay, Argentina, Costa Rica, Ecuador y España, establecen el derecho que toda persona posee para habitar en un ambiente que sea tanto ecológicamente equilibrado como pertinente y acertado para su desarrollo.

En México, el primer aspecto que despertó el interés del legislador por la protección del medio ambiente, fue evitar los daños a la salud, que la contaminación ambiental podía causar, en virtud de esto, decidió en 1971, realizar una reforma constitucional, en su artículo 73, frac. XVI, de este modo se aproximaba a la protección de medio ambiente a través de la protección de la salud humana.

Posteriormente mediante reforma de 1983, en el artículo 25 constitucional se adicionaron los conceptos de recursos productivos y de desarrollo sostenido, con esto se estableció el 
deber del Estado para apoyar e impulsar el desarrollo de los sectores social y privado de la economía, considerando el cuidado y conservación del medio ambiente. Así se inicia la conciliación entre el desarrollo económico y la protección del medio ambiente, reconociendo que no es posible intentar resolver los principales problemas económicos de un país con el riesgo de agotar las fuentes que en un inicio nos presentan las soluciones para esta problemática, es decir, resulta complejo resolver la escasez de empleo, así como de productos básicos agotando la fuentes de estos productos, ya que la solución sería únicamente temporal, y a la larga traería mayor escasez.

Nuevamente para fortalecer la capacidad del Estado para la protección del medio ambiente, se otorgó al Congreso de la Unión, la facultad de establecer la concurrencia del gobierno federal estatal y municipal, en el ámbito de sus respectivas competencias, para la protección del ambiente, la preservación y restauración del equilibrio ecológico, esto a través de la adición de la fracción XXIX-G del artículo 73 constitucional.

Posteriormente, se reconoció el derecho de toda persona a un medio ambiente adecuado para su desarrollo y bienestar como una garantía individual, en la reforma al artículo 4to constitucional, publicada en 28 de junio de 1999, aunque no se consiguió establecer la legitimación colectiva, para actuar en defensa del ambiente; como la mera inclusión de esta garantía no genera una mejora en el ambiente degradado, aunque facilita la utilización de los diversos mecanismos para protegerlo y restaurarlo, a partir del 9 de febrero de 2012, se reconoce la obligación del Estado de garantizar el respeto a este derecho, permitiendo la generación de legislación secundaria que permite la actuación tanto individual como colectiva en defensa del medio ambiente.

\title{
V. ANÁLISIS DE LA SENTENCIA DEL JUICIO DE AMPARO 753/2012 DEL JUZGADO SEGUNDO DE DISTRITO EN EL ESTADO DE CAMPECHE
}

En 2012 se presentó demanda de amparo que fue radicado bajo el expediente 753 del Juzgado Segundo de Distrito en el Estado de Campeche, en el que los quejosos como acto reclamado determinaron:

\begin{abstract}
PRIMERO. La expedición de un permiso a favor de la tercera perjudicada, relativo al evento ${ }^{* * *}$ $y$ en respuesta a la solicitud ${ }^{* * *}$, para la liberación al ambiente en fase comercial de soya (Glycine max L) genéticamente modificada solución Faena, destinada a sembrarse en 253,50o hectáreas en cinco polígonos que se ubican en,[... ], en los términos en los que se otorgó por las autoridades responsables, del cual esta parte pudo tener conocimiento completo hasta el pasado 6 de junio del presente año, a través del comunicado de prensa 276/12 emitido por el Servicio Nacional de Sanidad, Inocuidad y Calidad Agroalimentaria (SENASICA), incluido el permiso y todos los demás actos que se encuentren vinculados o sean consecuencia del mismo, en tanto incumplen el deber de garantía respecto del derecho a gozar de un medio ambiente sano, del derecho al trabajo y el derecho a la consulta previa, libre e informada de los pueblos indígenas;
\end{abstract}

Asimismo los quejosos manifestaron que [... haciendo consistir su interés en que son 'Representantes y autoridades de las comisarias, pertenecientes a un municipio de Campeche', y en su calidad de 'Indígenas Mayas' cuya principal actividad 'es la apicultura'. y a raíz de esto el Juez Segundo de Distrito en el Estado de Campeche tiene una obligación especial relativa al artículo $2^{\circ}$ de la Constitución Política de los Estados Unidos Mexicanos, para tomar en cuenta las costumbres y especificidades culturales en todos los juicios y procedimientos 
Organismos genéticamente modificados y reconocimiento de derechos indígenas: análisis de la sentencia de amparo 753/2012 del juzgado segundo de Distrito en el Estado de Campeche

en que los integrantes de comunidades indígenas sean parte individual o colectivamente, permitiendo el acceso pleno a la jurisdicción del Estado; así como sobre su derecho a la existencia de políticas necesarias para garantizar la vigencia de sus derechos y el desarrollo integral de sus comunidades, apoyando sus actividades productivas y el desarrollo sustentable. Mismo que reconoce y analiza mediante el argumento que:

[... ]este postulado, junto con el contenido del artículo $2^{\circ}$ constitucional que garantiza el acceso a la justicia individual o colectivamente a los grupos y comunidades indígenas, poseen plena fuerza vinculante al haberse adoptado en la normativa de nuestro país, lo que implica que permeé en todos los ámbitos del sistema jurídico, para crear un enfoque que al analizar el sistema de normas en su totalidad, cumpla con su objetivo, que no es otro que el ejercicio real de sus derechos y la expresión de su identidad individual y colectiva, para superar la desigualdad de oportunidades que tradicionalmente les ha afectado, lo cual se conoce como principio de transversalidad.

En este orden de ideas el Juez de Distrito, entró al análisis de la calidad que ostentan los quejosos en el juicio de amparo, argumentando que

[... ] además de ostentarse como tales promovieron demanda de amparo en su calidad de indígenas mayas cuya principal actividad es la apicultura, es decir, se autoidentificaron como indígenas pertenecientes a los mayas. Elemento suficiente para constatar la legitimación de los promoventes como indígenas, puesto que en los autos no existe prueba u objeción fundada que ponga en duda esa calidad o la desvirtué, por lo que, bajo una actitud orientada a favorecer la eficacia de los derechos de las personas que involucran grupos estructuralmente desventajados, debe privilegiarse su autoconciencia de indígenas, sobre la simple manifestación del tercero perjudicado para negárselas.

Dicha redacción resulta interesante en virtud de la aplicación del principio constitucional de progresividad en la que se hace un análisis extensivo de los autos y las pruebas que se encuentran en el expediente, desestimando la negativa de los terceros perjudicados para reconocerles la calidad de indígenas mayas. En dicho análisis cabe la pregunta ¿Qué pruebas y/o elementos deben de existir para otorgar la calidad de indígena?, debido a que el Juez de Distrito jamás determina elemento alguno que nos permita conocer los elementos constitutivos de para pertenecer a una persona indígena; pero en contraposición al argumento anteriormente citado, el hecho de manifestarse y autoidentificarse como un indígena transfiere la carga de la prueba a los terceros perjudicados y/o autoridades responsables.

Las autoridades responsables manifestaron como causales de improcedencia las determinadas por el artículo 73, fracción XII de la Ley de Amparo (vigente hasta el $1^{\circ}$ de abril de 2013) debido a que [... ]los actos reclamados derivan de otros ya consentidos[... ], ya que la expedición del permiso de liberación en etapa comercial deriva de otro consentido, esto es, de la expedición en etapa piloto de soya genéticamente modificada, para lo cual el órgano jurisdiccional consideró y determinó como infundadas en virtud de que dichos argumentos:

No pueden considerarse que el permiso otorgado para la liberación al ambiente en etapa comercial de soya genéticamente modificada sea un acto derivado de otro consentido, porque no es una consecuencia necesaria inminente de los diversos permisos expedidos para la misma liberación al ambiente de la soya genéticamente modificada en etapas experimental y piloto, ya que cada una de ella goza de autonomía e independencia, es decir, una no indefectiblemente 
da lugar a la expedición del permiso de la siguiente, sino que aun habiéndose otorgado el permiso para el programa piloto, y aun expedido este puede acontecer que se niegue el permiso para la fase comercial; además, conforme al artículo 32 de la Ley de Bioseguridad de Organismos Genéticamente Modificados, requieren de permiso las actividades de liberación experimental al ambiente, la liberación al ambiente en programa piloto y la liberación comercial al ambiente, de organismos genéticamente modificados, esto es, cada una de esas actividades es diferente a las otras [... ]

Asimismo las autoridades responsables manifestaron la actualización de la causal de improcedencia prevista en el artículo 73, fracción XV de la Ley de Amparo (vigente hasta el $1^{\circ}$ de abril de 2013) la cual prevé el principio de definitividad por no agotar la vía ordinaria correspondiente al acto reclamado el cual es contemplado por el artículo 69 de la Ley de Bioseguridad de Organismos Genéticamente Modificados; en este orden de ideas el órgano jurisdiccional determinó que:

[... ] el recurso de revisión contemplado por el artículo 69 de la Ley de Bioseguridad de Organismos Genéticamente Modificados, basta con mencionar que dicho numeral únicamente establece la posibilidad de que la Secretaria competente pueda revisar la vigencia de los permisos cuando se presente un cambio en las circunstancias de las actividades que puede influir en el resultado del estudio de la evaluación de los posibles riesgos en el cual se basó el permiso, o, se cuente con información científica o técnica adicional que pudiese modificar cualesquiera condiciones, limitaciones o requisitos del permiso, pero de ninguna manera constituye un recurso ordinario que deban agotar los particulares.

Es de suma importancia determinar las posibles consecuencias económicas, laborales y ambientales que a partir de la siembra de dicha extensión territorial con los OGMs de soya, si bien es cierto es difícil encontrar los posibles efectos secundarios que pudieran desarrollarse al efectuar la siembra, en virtud de que tendría que pasar un tiempo considerable para que se hicieran notar dichos efectos, pero tampoco se puede exponer al medio ambiente, sociedad y quejosos a ejecutar el acto reclamado y que los efectos que pudieran repercutirán en un tiempo futuro, así que por todo lo anterior, el Juez de Distrito [...] considera su especial situación frente al acto de autoridad, es decir, que podrían resultar afectados en sus bienes jurídicos (económicos, laborales, o ambientales) por las consecuencias que pudieran generar en las abejas la liberación o cultivo de la soya genéticamente modificadas.

En el derecho ambiental el principio de precaución es una de las herramientas para evitar el deterioro constante del medio ambiente; suele denominarse también como principio de cautela y surge de la búsqueda de herramientas que permitan la creación de instrumentos políticos, legales y de planeamiento más efectivos. Su fundamento científico se basa en la idea de que la ausencia de evidencia no es evidencia de ausencia, debido a que ante la amenaza de daños, considerados suficientemente serios, al medio ambiente o la salud humana no es necesario esperar alcanzar una certidumbre científica completa para tomar medidas protectoras.

Es con base en este principio que la comunidad deberá realizar actividades anticipatorias para prevenir daños, ya que cuando una actividad hace surgir amenazas del daño para el medio ambiente o la salud humana, se deben tomar medidas de precaución incluso si no se han establecido de manera completamente científica algunas relaciones de causa-efecto, en 
Organismos genéticamente modificados y reconocimiento de derechos indígenas: análisis de la sentencia de amparo 753/2012 del juzgado segundo de Distrito en el Estado de Campeche

virtud de que el retraso en el establecimiento de criterios de precaución permite la acumulación de daños.

En concreto, las ideas de precaución corresponden con el buen gobierno, ya que ante la duda de que una actividad sea riesgosa, es preferible limitarla, privilegiando la preservación del medio ambiente.

Por todo lo anterior y en aplicación de dicho principio para salvaguardar el bienestar del medio ambiente, el acceso a los recursos naturales, el desarrollo integral de los pueblos y comunidades; en este caso y desde la perspectiva de las minorías a los Mayas de la región, ¿Cuál es el límite cuando se aplica el principio de precaución?

Llegando a este punto nos encontramos con la necesidad apremiante del análisis de las actuaciones de las autoridades responsables, donde aparentemente cumplieron con sus obligaciones debido a que [... ]la protección efectiva de los derechos reconocidos a los indígenas requiere que se garantice el ejercicio de ciertos derechos humanos de indole procedimental, principalmente el acceso a la información, la participación en la toma de decisiones y el acceso a la justicia, en el entendido que los procedimientos necesarios para garantizar el acceso a la información, participación en la toma de decisiones y la justicia resulta de emplear lo que se conoce como consulta pública, razonamiento derivado del argumento jurisdiccional que determina que:

[... ] las autoridades tienen la obligación de consultar a los pueblos indígenas, mediante procedimientos apropiados y en particular a través de sus instituciones representativas, cada vez que se prevean medidas ya sean de carácter legislativo o administrativo, susceptibles de afectarles directa $o$ indirectamente; asimismo darles participación en la formulación, aplicación y evaluación de los planes y programas de desarrollo nacional y regional susceptibles de afectarles directamente; $y$ de establecer o mantener procedimientos con miras a consultar a los pueblos interesados, a fin de determinar si los intereses de esos pueblos serian perjudicados, y en qué medida, antes de emprender o autorizar cualquier programa de prospección y explotación de los recursos existentes en sus tierras.

En este orden de ideas y a través de la obligación que tienen las autoridades de consultar a las comunidades indígenas:

[... ] la Secretaria de Agricultura, Ganadería, Desarrollo Rural, Pesca y Alimentación, emitió un formato de opiniones públicas que puso a disposición del público en general, y en los cuales aparecen los siguientes datos:

Datos de la solicitud

Cultivo: Soya solución faena

Evento: $* * * * * * * * * * * * * * * * * *$

Numero de solicitud: $* * * * * * * * *$

Fenotipo Adquirido: Tolerancia a herbicidas que contienen glifosato

Sitio (s) de liberación: Península de Yucatán, Planicie Huasteca y Chiapas

Tipo de liberación: Comercial.

El órgano jurisdiccional [...] considera que el formato de opinión pública, antes aludido, no reúne los parámetros de consulta previa, culturalmente adecuada, informada, y de buena fe, establecidos en el Convenio 169 de la OIT sobre Pueblos Indígenas y Tribales en Países Independientes [...], por tal motivo y en este orden de ideas, es necesario examinar el criterio, 
requisitos esenciales e interpretación contemplados internacionalmente a la consulta a los pueblos indígenas debido a que:

El criterio de la Corte Interamericana de Derechos Humanos, al resolver el caso del Pueblo Indígena Kichwa de Sarayaku vs. Ecuador, el deber de consulta a los pueblos indígenas, debe contener como mínimo los siguientes parámetros:

a) La consulta debe ser previa. Debe realizarse durante las primeras etapas del plan o proyecto de desarrollo o inversión o de la concesión y no únicamente cuando surja la necesidad de obtener aprobación de la comunidad.

b) La consulta debe de ser culturalmente adecuada. El deber estatal de consultar a los pueblos indígenas debe cumplirse de acuerdo con sus costumbres y tradiciones, a través de procedimientos culturalmente adecuados y teniendo en cuenta sus métodos tradicionales para la toma de decisiones. Lo anterior exige que la representación de los pueblos sea definida de conformidad con sus propias tradiciones.

c) La consulta informada. Los procesos de otorgamiento exigen la provisión plena de información precisa sobre la naturaleza y consecuencias del proyecto a las comunidades consultadas, antes de y durante la consulta. Debe buscarse que tengan conocimiento de los posibles riesgos incluidos los riesgos ambientales y de salubridad, a fin de que acepten el plan de desarrollo o inversión propuesto, de forma voluntaria.

d) La consulta debe ser de buena fe, con la finalidad de llegar a un acuerdo. Se debe de garantizar, a través de procedimientos claros de consulta, que se obtenga su consentimiento previo, libre e informado para la consecución de dichos proyectos. La obligación del Estado es asegurar que todo proyecto en área indígena o que afecte su hábitat o cultura, sea tramitado y decidido con participación y en consulta con los pueblos interesados con vistas a obtener su consentimiento y eventual participación en los beneficios.

Dicho criterio internacional es vinculante para el Estado Mexicano, reúne cuatro requisitos esenciales que debe de reunir una consulta a un pueblo indígena, por tal motivo y con dichos elementos fácticos el Juez de Distrito determina que aun y cuando se llevó a cabo una consulta pública las autoridades [...] no cumplieron con otorgar a dichas comunidades indígenas el derecho de previa audiencia, así como tampoco atendieron la condición vinculante que tienen las opiniones emitidas por el Instituto Nacional de Ecología y la Comisión Nacional para el Conocimiento y Uso de la Biodiversidad [...]; siendo que dichas opiniones [...] tenían el carácter de vinculantes, es decir, obligatorios, para la decisión de otorgar o no el permiso para la liberación al ambiente en fase comercial de soya genéticamente modificada tolerante el glifosato.

El órgano jurisdiccional al atender a las opiniones presentadas por las autoridades determina que es de suma importa que:

[... ] para la liberación al ambiente en fase comercial de soya genéticamente modificada, puede afectar, de manera directa e indirecta, a dichas comunidades indígenas, se estima indispensable otorgarles derecho a audiencia previa a la emisión de dicho permiso, en forma eficaz, de buena $\mathrm{fe}$, previa, libre e informada, que asegure evitar cualquier perjuicio a sus integrantes colectivos o individuales, por virtud de la vinculatoriedad de dichos dictámenes, como por el derecho de los 
Organismos genéticamente modificados y reconocimiento de derechos indígenas: análisis de la sentencia de amparo 753/2012 del juzgado segundo de Distrito en el Estado de Campeche

pueblos de informarse y ser parte de las decisiones que tengan consecuencias directas de su comunidad. Cabe mencionar que el órgano jurisdiccional en cumplimiento del principio de prevención anteriormente mencionado determinó que:

[... ] el deber del Estado a la consulta para los pueblos y comunidades indígenas no depende de la demostración de una afectación real a sus derechos, sino de la susceptibilidad de que puedan llegar a dañarse, pues precisamente uno de los objetos del procedimiento es determinar si los intereses de los pueblos indígenas serian perjudicados.

Los procesos que garanticen el derecho a la consulta pública de los pueblos indígenas deben de ser efectivos, y en el razonamiento de mostrar una efectividad plena es necesario que se lleven a cabo con antelación a la toma de la decisión por parte de la autoridad, por lo que se determinó que:

[... ] para que la autoridad cumpla con el debido proceso, deberá adoptar las medidas necesarias para que la consulta pública se lleve a cabo directamente en las comunidades indígenas asentadas en los Municipios, [...], área que comprende la solicitud de la empresa ${ }^{\star * *}$, a través de los representantes o autoridades reconocidas por la propia comunidad, y por los medios que den certeza, como podría ser, por ejemplo, mediante asambleas convocadas con anticipación, o por algún otro medio que garantice que las comunidades tuvieron pleno conocimiento de esa consulta pública.

Sin embargo, el 26 de noviembre de 2012 se publicó en el DOF el Reglamento Interior de la Secretaria de Medio Ambiente y Recursos Naturales, mismo que en su transitorio segundo abrogó el anterior Reglamento Interior de la Secretaría de Medio Ambiente y Recursos Naturales; decreto que modificó las condiciones para la emisión de los permisos para la liberación al ambiente en fase comercial de OGM, ya que en su artículo 28, dispuso como facultad de la Dirección General de Impacto y Riesgo Ambiental emitir el dictamen de bioseguridad cuando se trate de los permisos de liberación experimental, de liberación en programa piloto; y de liberación comercial de organismos genéticamente modificados, competencia de la Secretaría de Agricultura, Ganadería, Desarrollo Rural, Pesca y Alimentación, previa opinión técnica, análisis y evaluación de riesgo de la Comisión Nacional para el Conocimiento y Uso de la Biodiversidad y, en su caso, opinión de la Comisión Nacional de Áreas Naturales Protegidas, eliminando la obligatoriedad de esas opiniones.

\section{CONCLUSIONES Y PROPUESTAS}

El derecho a un medio ambiente sano, el derecho a la vida y el derecho a la participación en la toma de decisiones por parte de los grupos indígenas constituyen derechos fundamentales inherentes al hombre, están legitimados para ser protegidos por la legislación mexicana, por lo que resulta indispensable considerarlos todos, para la toma de decisiones en relación con la administración de los recursos naturales.

Dichos derechos requieren un no hacer de la autoridad a efecto de no inhibir su libre ejercicio, pero necesitan también un hacer estatal que permita la participación de las comunidades indígenas involucradas o posiblemente afectadas, ya que no puede haber desarrollo pleno, sin la participación comunitaria.

La defensa del medio ambiente, se enfoca desde una perspectiva antropocéntrica y siendo que la protección de un Derecho humano no debe verse oscurecida por la protección a otro 
derecho fundamental, o el cumplimiento de una obligación Estatal -como la rectoría del desarrollo nacional, el fomento del crecimiento económico, el empleo, la planeación, conducción, coordinación y orientación de la actividad económica nacional, regulación y fomento de actividades económicas- resulta complicada la toma de decisiones que encuentren el punto de equilibrio en donde ninguno de los derechos se vea mermado.

Para lograr este punto de equilibrio, resulta indispensable modificar, agregando a la Ley de Bioseguridad de Organismos Genéticamente Modificados, la consideración de que los resultados de las consultas públicas a las comunidades que pudieran verse afectadas, deberán incluirse entre los documentos que habrán de acompañar a las solicitudes de permisos para liberación al ambiente de OGMs.

Esto implica modificación de la norma en comento, incluyendo el resultado de consultas públicas a las comunidades, para el trámite de permisos para liberación de OGMs; agregándolo en su artículo 42, sobre permiso para liberación experimental al ambiente, en una fracción VIII; en su artículo 50, sobre permiso para liberación al ambiente en programa piloto, en una fracción VI; del artículo 55, sobre permiso para liberación comercial al ambiente, en una fracción VIII.

Es necesario también agregar que los resultados de las consultas públicas a las comunidades que pudieran verse afectadas, deberán incluirse en la información que habrá de acompañar a las solicitudes de autorización de OGMs, que resultan necesarias cuando dichos organismos se destinen a: uso o consumo humano, al procesamiento de alimentos para consumo humano, a finalidades de salud pública, o a la biorremediación.

Lo que significa modificación del artículo 92 de la ley en comento, sobre solicitud de autorización de un OGM, incluyéndolo en una fracción III.

Los mecanismos para realizar las consultas públicas y la participación de pueblos y comunidades indígenas de las zonas en que se pretenda la liberación de OGMs deberán establecerse claramente.

Para lo cual se requiere modificación al artículo 108 de la Ley de Bioseguridad de Organismos Genéticamente Modificados, eliminándole a la Comisión Intersecretarial de Bioseguridad de los Organismos Genéticamente Modificados (CIBIOGEM) la facultad de establecer dichos mecanismos; así como modificación al artículo 54 del Reglamento de la Ley de Bioseguridad de Organismos Genéticamente Modificados, en el que deberán describirse procedimientos y requisitos para la realización de las consultas que sean acordes con el criterio de la Corte Interamericana de Derechos Humanos al respecto.

Los dictámenes de bioseguridad requeridos para el otorgamiento de los permisos para la realización de actividades con OGMs, deberán tener carácter vinculante para las secretarías que otorgan dichos permisos o autorizaciones -SEMARNAT, SAGARPA, SSA-, lo cual se logra mediante modificación del artículo 66 de la Ley de Bioseguridad de Organismos Genéticamente Modificados, así como el artículo 15 del Reglamento de la Ley de Bioseguridad de Organismos Genéticamente Modificados, para que estos incluyan la necesidad de considerar dichos dictámenes en toda emisión de permiso o autorización para actividades con OGMs. 


\section{FUENTES}

\section{DOCUMENTOS ELECTRÓNICOS}

Bioseguridad para OGM. Página web de Servicio Nacional de Sanidad, Inocuidad y Calidad Agroalimentaria. Disponible en: http://www.senasica.gob.mx/?id=2403;

Bioseguridad para Organismos Genéticamente Modificados. Página web del Servicio de Sanidad, Inocuidad y Calidad Agroalimentaria. 2015. Disponible en: http://www.senasica.gob. $\mathrm{mx} /$ ? id=2403;

Frequently asked questions on genetically modified foods. Página web de la Organización Mundial de la Salud. Disponible en: http://www.who.int/foodsafety/areas_work/ food-technology/faq-genetically-modified-food/en/\#;

Los organismos modificados genéticamente, los consumidores, la inocuidad de los alimentos y el medio ambiente. Organización de las Naciones Unidas para la Agricultura y la Alimentación. Roma, 2001. Disponible en: ftp://ftp.fao.org/docrep/fao/oo3/x9602s/ x9602soo.pdf;

\section{NORMATIVAS INTERNACIONALES}

Convenio 169 sobre pueblos indígenas y tribales en países independientes, de la Organización Internacional del Trabajo; Ginebra, Suiza, 1989.

Protocolo de Cartagena Sobre Seguridad de la Biotecnología. Texto y Anexos. Montreal, Canadá, 2000.

Constitución Política de los Estados Unidos Mexicanos.

Ley de Bioseguridad de Organismos Genéticamente Modificados.

Reglamento de la Ley de Bioseguridad de Organismos Genéticamente Modificados.

Sentencia del juicio de amparo 753/2012 del juzgado segundo de distrito en el estado de Campeche. 
